\title{
Hypnosis in pediatrics: applications at a pediatric pulmonary center Ran D Anbar
}

Address: Associate Professor of Pediatrics and Medicine, Department of Pediatrics, Upstate Medical University, 750 E. Adams Street, Syracuse, NY 13210, USA

E-mail: Anbarr@mail.upstate.edu

Published: 3 December 2002

BMC Pediatrics 2002, 2:11
Received: 12 August 2002

Accepted: 3 December 2002

This article is available from: http://www.biomedcentral.com/I47I-243I/2/II

(C) 2002 Anbar; licensee BioMed Central Ltd. This is an Open Access article: verbatim copying and redistribution of this article are permitted in all media for any purpose, provided this notice is preserved along with the article's original URL.

Keywords: Anxiety, asthma, habit cough, hypnosis, shortness of breath, vocal cord dysfunction

\section{Abstract}

Background: This report describes the utility of hypnosis for patients who presented to a Pediatric Pulmonary Center over a 30 month period.

Methods: Hypnotherapy was offered to 303 patients from May I, 1998 - October 3I, 2000. Patients offered hypnotherapy included those thought to have pulmonary symptoms due to psychological issues, discomfort due to medications, or fear of procedures. Improvement in symptoms following hypnosis was observed by the pulmonologist for most patients with habit cough and conversion reaction. Improvement of other conditions for which hypnosis was used was gauged based on patients' subjective evaluations.

Results: Hypnotherapy was associated with improvement in $80 \%$ of patients with persistent asthma, chest pain/pressure, habit cough, hyperventilation, shortness of breath, sighing, and vocal cord dysfunction. When improvement was reported, in some cases symptoms resolved immediately after hypnotherapy was first employed. For the others improvement was achieved after hypnosis was used for a few weeks. No patients' symptoms worsened and no new symptoms emerged following hypnotherapy.

Conclusions: Patients described in this report were unlikely to have achieved rapid improvement in their symptoms without the use of hypnotherapy. Therefore, hypnotherapy can be an important complementary therapy for patients in a pediatric practice.

\section{Background}

While our understanding of the nature hypnosis is complex and contested, it is rapidly evolving. [1-6] In practice it can be useful to think of hypnosis as an altered state of consciousness, and hypnotherapy as a treatment modality utilizing hypnosis to achieve a therapeutic goal. [1]

The state of hypnosis is a natural mental state. [4] For example: When engaged in imaginary play children are of- ten in a state of self-hypnosis; when bored in a classroom students sometimes use self-hypnosis to imagine themselves engaged in an activity elsewhere; and mental rehearsal of a performance is often done in a state of selfhypnosis.

There are many popular misconceptions regarding hypnosis: $[4,5]$ Hypnotherapy does not involve one person controlling another's mind, inducing sleep, inducing forced 
amnesia, or causing individuals to do things against their will. The stage hypnotist, who appears to be controlling his subjects, first enlists their cooperation by asking for volunteers, and then picks subjects who can use hypnosis easily. [7] Thus, a stage hypnotist uses his subjects' hypnotic capacity for entertainment, and not for therapeutic benefit.

In addition to therapist-assisted hypnosis, patients can be taught to use self-hypnosis to achieve desired effects. $[1,4,5,8]$ Hypnosis is useful in altering thoughts, feelings, expectations, attitudes, perception, behavior, and even physiology. $[1,4,6]$ Therefore, hypnotherapy can be used to treat anxiety, pain, discomfort, to change habits, or as an aid in differential diagnosis. [6] For example, a symptom that clears with the use of hypnosis-induced relaxation may have a psychological component. However, as hypnosis has been demonstrated to have physiologic effects, e.g. on airway reactivity, blood flow and immune response, [1] benefits of hypnosis may be attributable to resultant alterations of physiology.

Hypnotherapy often is utilized to complement medical therapy. [1,5] However, use of hypnosis sometimes can replace pharmacological therapy, e.g. for the treatment of phlebotomy-associated pain or migraine headaches. [1] The practitioner who uses hypnotherapy should keep in mind that sometimes patients are referred for hypnotherapy with an organic condition for which hypnosis is not an appropriate therapy. [9]

Because of their natural practice in the use of their imagination, most children readily use hypnosis. [10] A fundamental theme of pediatric hypnosis is to help children develop their own abilities and ownership of self-regulation strategies. [1] Thus, it is important to ensure that it becomes the child's desire to use hypnosis as therapy, otherwise the child is unlikely to cooperate, and the hypnosis is less likely to be successful. $[1,4,5]$ For example, patients have different abilities to use visual, auditory, tactile, kinesthetic, or olfactory imagery. Therefore, the hypnotherapist should offer hypnotic imagery that is based on the patient's interests and abilities.

The parents' role in hypnotherapy is based on their involvement with the child's condition, the child's age, the child's needs for autonomy, and the parents' willingness and ability to participate in the hypnotherapeutic process. [11] Older children often are given the opportunity to learn about hypnosis outside of their parents' presence in order to minimize their anxiety about successful performance, or to allay concerns about parental interference. [11]

In order to demonstrate the utility of hypnotherapy in a pediatric practice, this report describes how it was used ef- fectively by a pediatric pulmonologist during his first 30 months of experience with hypnosis.

\section{Methods}

Hypnotherapy was offered to 303 patients presenting to the Pediatric Pulmonary Center in Syracuse, NY from May 1, 1998 - October 31, 2000 (constituting approximately $10 \%$ of all patients at the Center during the 30 month period). Patients offered hypnotherapy included those thought to have pulmonary symptoms attributable to psychological issues (e.g. habit cough, or anxiety induced shortness of breath), discomfort due to medications, or fear of procedures. Patients who remained symptomatic despite aggressive medical management also were offered hypnosis since psychological factors may cause symptoms in some of these patients. [12] Patients were encouraged to identify issues for which they might use hypnosis. Several patients asked for and received suggestions about how to use hypnosis to ameliorate non-pulmonary symptoms such as abdominal pain, headaches, and insomnia, or to help improve their school or athletic performance.

Patients were taught self-hypnosis by their pediatric pulmonologist, who had received training in hypnotherapy through two 20-hour hypnosis workshops offered by the American Society of Clinical Hypnosis and the Society for Developmental and Behavioral Pediatrics.

For many of the patients described in this report, the initial hypnosis session took approximately 45 minutes. This session usually consisted of: (I) A pre-hypnotic interview, during which the concept of hypnosis was introduced to the children and their parents. Concerns or misconceptions regarding hypnosis were addressed at this time. (II) Hypnosis induction and deepening were dependent on the patients' developmental level, and based on the patients' aptitude and preference. [1,13] Thus, the children learned that the hypnosis experience was in their control. Typically, children chose to imagine a favorite place. (III) Patients were taught to relax with aid of hypnosis, and how to employ imagery specific to their symptom. For example, some patients learned to imagine the appearance of their airways when they were symptomatic, and to imagine changing the appearance to a normal one. Patients sometimes were given the suggestion that their subconscious would take care of their problem before they would become consciously aware of it. (IV) Prior to trance termination patients were instructed to give themselves suggestions for improvement regarding issues of importance to them. $[4,5](V)$ Following the hypnosis sessions, the experience was discussed with the patients and parents. The patients were reminded that improvements with hypnosis can take time, and that with practice more improvement can be expected. 
Alteration of pain or taste perception often was taught in a few minutes, by suggesting that the patient imagine being in a relaxing place, followed by a suggestion that yielded the desired change in perception. [14]

Fifty-three of the patients met with the pulmonologist to work exclusively on hypnosis for a second session. Thereafter, only 22 patients requested that further sessions be devoted solely to hypnosis. For all other patients use of hypnosis was integrated into their regular 15-30 minute medical follow-up visits. Within these visits, reinforcement of hypnosis work usually took less than five minutes. Patients were encouraged to practice self-hypnosis at home for at least a few minutes on a daily basis until their symptom resolved or improved.

The outcome of hypnotherapy was determined by patients' answers to open-ended questions posed orally by the pulmonologist, regarding their subjective evaluation of the efficacy of their use of hypnosis. For most patients with habit cough or conversion reaction, initial assessment of change in symptoms was accomplished during the first hypnosis visit. Also, most patients demonstrated their control of pain or taste perception immediately following their initial hypnosis instruction. For patients who used hypnosis for other conditions, assessment of change in symptoms was gauged during follow-up visits. For example, patients were asked whether they had used hypnosis, and whether they felt their symptoms improved as a result of its use.

As this report describes a retrospective chart audit without identification of patients, it was eligible for exemption from review by an institutional review board.

\section{Results}

Tables 1 and 2 list the reasons for which hypnotherapy was offered to 303 patients, the number of patients who agreed to be taught hypnosis, and the outcome reported by these patients following hypnosis. Twenty-eight patients declined to use hypnosis for various reasons including that it was against their religion, or because they felt their symptoms were unlikely to respond to hypnosis. Twenty-one patients were lost to follow-up following an initial hypnosis session. The remaining 254 patients constitute the cohort for whom results are reported. Fifty-six of these patients were offered hypnotherapy for more than one reason.

The primary diagnoses of the patients are listed in Table 3. Eleven of the patients with cystic fibrosis were 21-49 years old. The average age of the 243 pediatric patients in this report was 12.2 years (range 5-20).
In this patient population, $81 \%$ of patients who used hypnosis improved. When improvement was reported, in some cases symptoms resolved immediately after the first session of hypnotherapy. In other cases improvement was achieved after hypnosis was used for a few weeks. No patients' symptoms worsened and no new symptoms emerged following hypnotherapy. There was no improvement in any symptoms for 50 patients. Of these patients, only 18 chose to use hypnosis following the initial instruction session.

Hypnotherapy was used for patients with pulmonary symptoms such as asthma, chest pain/pressure, habit cough, hyperventilation, shortness of breath, sighing and vocal cord dysfunction. None of these patients previously had responded adequately to therapy with medications. It is notable that $80 \%$ of these patients improved following use of hypnosis.

The patients with asthma who reported improvement stated that the frequency and intensity of their respiratory distress episodes had improved with use of hypnosis.

With the exception of one patient who was lost to followup, all 14 patients who complained of chest pain, chest tightness, hyperventilation, or sighing reported resolution of their symptoms after one or two sessions of hypnosis.

Habit cough stopped after one session of hypnosis for 12 of the 19 patients. The cough resolved within 6 weeks after the first hypnosis session for an additional four patients.

Of the 42 patients with shortness of breath, 22 had normal lung function at rest, as measured by pre- and postbronchodilator spirometry. Of these 22, 16 achieved resolution of their symptom following hypnosis, and four reported improvement. In contrast, of the 20 patients with abnormal lung function at rest, only 2 achieved resolution of their shortness of breath, but nine reported improvement.

Among the 29 patients diagnosed as having vocal cord dysfunction, the symptom resolved for 11 and improved for 9 others after a single hypnosis session. Notably, vocal cord dysfunction was diagnosed by laryngoscopy in 5 of the patients, while in the remaining patients it was diagnosed based on symptoms such as inspiratory stridor with exercise, and/or blunting of the inspiratory loop during pulmonary function testing.

Sixteen patients declined to use hypnosis for pulmonary symptoms (asthma, habit cough, shortness of breath or vocal cord dysfunction) and continued to receive standard medical therapy. Among these patients, symptoms im- 
Table I: Medical Reasons for which Hypnotherapy was Offered at the Pediatric Pulmonary Center

\begin{tabular}{|c|c|c|c|c|c|}
\hline $\begin{array}{l}\text { Reason for } \\
\text { Hypnosis }\end{array}$ & $\begin{array}{l}\text { Hypnosis } \\
\text { Offered }\end{array}$ & $\begin{array}{l}\text { Hypnosis } \\
\text { Accepted }\end{array}$ & $\begin{array}{l}\text { Symptom } \\
\text { Improved }\end{array}$ & $\begin{array}{l}\text { Symptom Not } \\
\text { Improved }\end{array}$ & $\begin{array}{l}\text { Lost to } \\
\text { Follow-up }\end{array}$ \\
\hline \multicolumn{6}{|c|}{$\begin{array}{c}\text { (Number of patients) } \\
\text { Pulmonary }\end{array}$} \\
\hline Asthma & 25 & 21 & 8 & 7 & 6 \\
\hline Chest pain/pressure & 10 & 10 & 9 & 0 & I \\
\hline Habit cough & 23 & 19 & 16 & 2 & 1 \\
\hline Hyperventilation & 4 & 4 & 4 & 0 & - \\
\hline Shortness of breath & 46 & 42 & 31 & 6 & 5 \\
\hline Sighing & 1 & 1 & 1 & 0 & - \\
\hline Vocal cord dysfunction & 33 & 29 & 20 & 2 & 7 \\
\hline
\end{tabular}

Gastrointestinal

\begin{tabular}{lccccc}
\hline & & & 4 & 5 & 1 \\
Abdominal Pain & 11 & 10 & 3 & 1 & - \\
Anticipatory nausea & 4 & 4 & 1 & 1 & - \\
Appetite stimulation & 3 & 2 & 1 & 0 & - \\
Constipation & 1 & 1 & 3 & 4 & 2 \\
Heartburn & 10 & 9 & & \\
\hline
\end{tabular}

Neurological

\begin{tabular}{lccccc}
\hline Headaches & 16 & 16 & 9 & 7 & - \\
Sleep Disturbance & 18 & 17 & 15 & 2 & - \\
Tic & 1 & 1 & 1 & - & 37 \\
\hline Total & 206 & 186 & 126 & 23 \\
\hline
\end{tabular}

proved within a year for three of four with habit cough, and two of four with vocal cord dysfunction. The other 11 patients did not improve.

\section{Discussion}

As illustrated by this report, hypnotherapy can provide therapy for patients presenting to a Pediatric Pulmonary Center. Many of the patients were unlikely to have achieved rapid improvement of their symptoms without use of hypnosis. It is possible that some of the improvement attributed to hypnosis was a result of the increased attention provided by the clinician while teaching hypnosis. However, hypnotherapy without suggestions directed at a specific symptom, as well as directed suggestions without use of hypnosis, often do not yield improvement. $[1,4]$ It also is possible that a reporting bias may have falsely increased the apparent success of hypnosis in this study, because patients wanted to please their treating physician. The impact of this possibility may be minimal, as many of the patients helped by hypnosis had reported little or no improvement with previous therapies suggested and applied by the same physician.

The potential mechanisms by which hypnosis may have helped these patients are varied. For example, the improvement for the patients with asthma may have been the result of physiologic changes induced by hypnosis. [15] On the other hand, the patients with shortness of breath may have developed anxiety or panic as a result of recurrent episodes of asthma-associated shortness of breath. [16,17] Such anxiety could have caused further shortness of breath and vocal cord dysfunction, which can cause stridor. [12,16,18] Hypnotherapy may have been useful for these patients because anxiety is very amenable 
Table 2: Non-Medical Reasons for which Hypnotherapy was Offered at the Pediatric Pulmonary Center

\begin{tabular}{|c|c|c|c|c|c|}
\hline Reason for Hypnosis & $\begin{array}{l}\text { Hypnosis } \\
\text { Offered }\end{array}$ & $\begin{array}{l}\text { Hypnosis } \\
\text { Accepted }\end{array}$ & $\begin{array}{l}\text { Symptom } \\
\text { Improved }\end{array}$ & $\begin{array}{l}\text { Symptom Not } \\
\text { Improved }\end{array}$ & $\begin{array}{l}\text { Lost to } \\
\text { Follow-up }\end{array}$ \\
\hline \multicolumn{6}{|c|}{$\begin{array}{c}\text { (Number of patients) } \\
\text { Psychological }\end{array}$} \\
\hline Anxiety & 62 & 57 & 45 & 7 & 5 \\
\hline $\begin{array}{l}\text { Compliance with ther- } \\
\text { apy }\end{array}$ & 15 & 11 & 6 & 5 & - \\
\hline Conversion reaction & I & 1 & 1 & 0 & - \\
\hline Smoking cessation & I & 1 & 0 & I & - \\
\hline
\end{tabular}

latrogenic

\begin{tabular}{lccccc}
\hline & & & 29 & 2 & - \\
Medication Taste & 35 & 31 & 38 & 5 & - \\
Medical procedure pain & 48 & 43 & 3 & 0 & - \\
Post-operative pain & 3 & 3 & & \\
\hline
\end{tabular}

At Patient Request

\begin{tabular}{lccccc}
\hline School performance & 9 & 9 & 7 & 1 & 0 \\
Sports performance & 5 & 5 & 5 & 1 & - \\
\hline Total & 179 & 161 & 134 & 6 \\
\hline
\end{tabular}

to treatment with hypnosis. [2,4] Additionally, patients who successfully utilized hypnosis in this report may have benefited from the increased feeling of self-mastery provided by its application. [1,19-21]

The potential utility of hypnosis for respiratory problems is illustrated further by the usual treatment for vocal cord dysfunction. This typically involves speech therapy techniques $[12,18]$ that are analogous to hypnotherapeutic strategies, both in developing focused concentration, training a ritualistic behavior, and repetitive "practice" with concentration and relaxation. Similarly, patients with habit cough have been reported to improve with use of suggestion therapy [22] that probably represents a form of hypnosis.

Limitations of this report include its retrospective nature that precludes a consistently organized analysis of the effects of hypnosis in this patient population. Additionally, bias was likely introduced, as the results and conclusions in this report are largely based on subjective assessments of outcome, which were probably influenced by the expectations of both the patients and the clinician.

Children are especially adept at learning to use hypnosis, $[10,13,23]$ which may account for the high rate of reported success. The success rate may also have been high because hypnosis was offered to patients who were likely to benefit, such as those with anxiety or those for whom medical therapy was not helpful. On the other hand, many of the instances in which little or no improvement was noted might have been avoided had the clinician had more than 30 months of experience in assessing the patients' initial attitude. Thus, some of the 32 patients who did not use hypnosis on their own and reported no improvement in their symptoms might not have been offered initial instruction at that time by a more experienced clinician. Other patients may have been more successful if increased rapport was established, or if different imagery was employed. Further, it is possible that with practice hypnosis might have become beneficial for some of the patients who initially reported no improvement. 
Table 3: Primary Diagnoses of Patients Using Hypnosis at the Pediatric Pulmonary Center

\begin{tabular}{lc}
\hline & $\begin{array}{c}\text { Number of } \\
\text { Patients }\end{array}$ \\
\hline Asthma & 135 \\
Cancer & 11 \\
Chest Pain & 2 \\
Cystic Fibrosis & 51 \\
Gastroesophageal Reflux & 3 \\
Habit Cough & 16 \\
Immotile Cilia Syndrome & 1 \\
Interstitial Lung Disease & 1 \\
Myopathy & 2 \\
Obstructive Sleep Apnea & 1 \\
Shortness of breath & 8 \\
Spinal Muscular Atrophy & 1 \\
Vocal Cord Dysfunction & 22 \\
\hline & \\
\hline Total & $\mathbf{2 5 4}$ \\
\hline
\end{tabular}

A common concern among clinicians contemplating the addition of hypnosis to their clinical practice is the perception that hypnotherapy requires too much time, both for assessment of patient readiness, and for hypnotherapy itself. However, most of the patients in this report benefited from hypnosis despite the time limitation imposed by a medical setting. Additionally, for many patients in this report use of hypnosis actually saved time and expense. For example, a patient with habit cough might undergo multiple investigations and receive numerous medications in evaluation and treatment of his symptom. [22] For the majority of patients with habit cough in this report, hypnotherapy was curative after a single session. Some hypnotherapeutic interventions require a large number of sessions. [6] Patients needing more time than is available in a medical setting may be referred to individuals specializing in hypnotherapy (usually psychiatrists, psychologists, or social workers).

Another concern of clinicians is that one must have substantial training and experience to be able to use hypnosis effectively. The patients in this report were treated by a motivated physician in his first 30 months of offering hypnotherapy. Therefore, it appears possible that use of hypnosis can be learned rapidly and thereafter used effectively.

Use of hypnotherapy is one of several treatment options that attempt to affect patients' physiological response by inducing a change in their mental processes. Other meth- ods based on the same principle include biofeedback, [24] meditation, [25] relaxation training, [26] and utilization of the placebo effect as therapy. [27] Future blinded and controlled research protocols should help define optimal psychological therapeutic approaches for children, delineate the proportion of a pediatric population that may benefit from hypnosis, and identify hypnotherapeutic suggestions that are most likely to be successful for children.

Aside from successful use of hypnosis in a pediatric pulmonology practice, as described in this report, other common pediatric problems that have been demonstrated to be amenable to treatment with hypnosis include attentional disorders, chronic pain, functional abdominal pain, enuresis, migraine headaches, nail biting, and thumb sucking. $[1,2,4,5,13,28]$

\section{Conclusions}

By learning about hypnosis, pediatricians will be able use an additional form of treatment for many different symptoms. Also, pediatricians may learn about better ways of interacting with their patients without use of "formal" hypnosis. For example, they can learn to identify and utilize spontaneous hypnotic states in their patients, [29] or learn to induce such states with story telling or blowing bubbles. [13] As a result of work with hypnosis, pediatricians also will become more aware of the importance of using an encouraging and positive approach with their patients, as well as effective use of body language. [2]

Use of hypnosis is a skill most children can learn. [1] As child advocates, pediatricians should consider teaching this skill to their patients, as it can become an invaluable tool for a large number of these individuals.

\section{Competing interests}

None declared.

\section{Author's contributions}

The author is the pediatric pulmonologist described in this article. He used hypnosis with all the patients described. He wrote the manuscript.

\section{Acknowledgements}

The author gratefully acknowledges the suggestions and editorial comments made by Drs. Daniel P. Kohen, Shoshana T. Melman, and Karen Olness, during the preparation of this manuscript.

\section{References}

I. Olness K, Kohen DP: Hypnosis and hypnotherapy with children. New York, NY: The Guilford Press 1996

2. Hammond DC, ed: Handbook of hypnotic suggestion and metaphors. New York, NY: WW Norton \& Company 1990

3. Lynn S], Rhue JW, eds: Theories of hypnosis: current models and perspectives. New York, NY: The Guilford Press 1991

4. Udolf R: Handbook of hypnosis for professionals. Northvale, NJ: Jason Aronson 1987 
5. Waxman D: Hartland's medical and dental hypnosis. London, England: Bailliere Tindall 1989

6. Margolis CG: Hypnotic trance. The old and the new. Primary Care 1997, 24:809-823

7. Kreskin: The secrets of the amazing kreskin. Buffalo, NY: Prometheus Books 1991

8. Gardner GG: Teaching self-hypnosis to children. Int J Clin Exp Hypn 198I, 29:300-312

9. Olness K, Libbey P: Unrecognized biological bases of behavioral symptoms in patients referred for hypnotherapy. Am J Clin Hypn 1987, 30: I-8

10. London P: Developmental experiments in hypnosis. J Proj Tech Pers Assess 1965, 29:189-199

1I. Gardner GG: Parents: obstacles or allies in child hypnotherapy? Am J Clin Hypn 1974, 22:20-38

12. Fritz GK, Fritsch S, Hagino O: Somatoform disorders in children and adolescents: a review of the past 10 years. J Am Acad Child Adolesc Psychiatry 1997, 36:1329-1338

13. Sugarman LI: Hypnosis: teaching children self-regulation. Pediatr $\operatorname{Rev}$ 1996, 17:5-II

14. Anbar RD: You don't like the taste of your medication? So change the taste! Clin Pediatr (Phila) 2002, 41:197-198

15. Hackman RM, Stern JS, Gershwin ME: Hypnosis and asthma: a critical review. J Asthma 2000, 37:1-15

16. Anbar RD: Self-hypnosis for management of chronic dyspnea in pediatric patients. Pediatrics 200I, 107(2):E2I [http:// www.pediatrics.org/cgi/content/full//07/2/e2I]

17. Baron C, Marcotte JE: Role of panic attacks in the intractability of asthma in children. Pediatrics 1994, 94:108-110

18. Anbar RD, Hehir DA: Hypnosis as a diagnostic modality for vocal cord dysfunction. Pediatrics 2000, I06:E8I [http://www.pediatrics.org/cgi/content/full//06/6/e8I]

19. Anbar RD: Self-hypnosis for patients with cystic fibrosis. Pediatr Pulmonol 2000, 30:461-465

20. Anbar RD: Of mind, body, and modern technology. Clin Pediatr (Phila) 2000, 39:433-436

21. LeBaron S, Zeltzer LK: The role of imagery in the treatment of dying children and adolescents. J Dev Behav Pediatr 1985, 6:252258

22. Lokshin B, Lindgren S, Weinberger M, Koviach J: Outcome of habit cough in children treated with a brief session of suggestion therapy. Ann Allergy 1991, 67:579-582

23. London $P$, Cooper LM: Norms of hypnotic susceptibility in children. Dev Psychol 1969, I: I 13-124

24. Culbert TP, Kajander RL, Reaney JB: Biofeedback with children and adolescents: clinical observations and patient perspectives. J Dev Behav Pediatr 1996, 17:342-350

25. Jevning R, Wallace RK, Beidebach M: The physiology of meditation: a review. A wakeful hypometabolic integrated response. Neurosci Biobehav Rev 1992, 16:41 5-424

26. Richter NC: The efficacy of relaxation training with children. Abnorm Child Psychol 1984, 12:319-344

27. Straus JL, von Ammon Cavanaugh S: Placebo effects. Issues for clinical practice in psychiatry and medicine. Psychosomatics 1996, 37:315-326

28. Anbar RD: Self-hypnosis for treatment of functional abdominal pain in childhood. Clin Pediatr (Phila) 200I, 40:447-45I

29. Gall JC: The art of examining a child: Use of naturalistic methods in pediatric physical examination. Eriksonian Monographs 1990, 7:69-85

\section{Pre-publication history}

The pre-publication history for this paper can be accessed here:

http://www.biomedcentral.com/1471-2431/2/11/prepub
Publish with BioMed Central and every scientist can read your work free of charge

"BioMedcentral will be the most significant development for disseminating the results of biomedical research in our lifetime."

Paul Nurse, Director-General, Imperial Cancer Research Fund

Publish with BMC and your research papers will be:

- available free of charge to the entire biomedical community

- peer reviewed and published immediately upon acceptance

- cited in PubMed and archived on PubMed Central

- yours - you keep the copyright

Submit your manuscript here:

http://www.biomedcentral.com/manuscript/

BioMedcentral.com editorial@biomedcentral.com 